\title{
Summative Evaluation of a Malnutrition Program for Children in the Dominican Republic
}

\author{
Lauri Wright ${ }^{1, *}$, James Epps ${ }^{2}$, \\ ${ }^{1}$ Department of Community and Family Health,University of South Florida,13201 Bruce B. Downs Blvd Tampa, FL 33612, USA \\ ${ }^{2}$ Department of Mental Health Law \& Policy,University of South Florida,13201 Bruce B. Downs Blvd, Tampa, FL 33612, USA \\ *Corresponding Author: lywright@usf.edu
}

Copyright (C) 2014 Horizon Research Publishing All rights reserved.

\begin{abstract}
Due to the prevalence and impact of childhood undernutrition, the objective of the study was to investigate causes of malnutrition and evaluate the effectiveness of a Nutrition-Supplementation Program (NSP) in rural Dominican Republic with and without nutrition counseling. Causes of undernutrition were examined by qualitative interviews conducted with parents. Program effectiveness was measured by comparing children's pre- and post-percentage goal weight/age. The most prevalent contributors of malnutrition found were food insecurity, disease, poor maternal and child health policies, and lack of knowledge. Children who received only milk and vitamin supplementation did not improve \% goal weight/age (MEAN pre $=77.3 ;$ MEAN post $=78.1 ; \mathrm{t}=0.21 ; \mathrm{p}<.83$ ). Children who had both nutrition counseling and supplementation improved markedly (MEAN pre $=67.2$, MEAN post $=78.2 ; \mathrm{t}=3.01 ; \mathrm{p}<.07)$. Because of the complexity of malnutrition, programs are most successful when multiple interventions including nutritioncounseling are provided.
\end{abstract}

Keywords Malnutrition, Children, Evaluation,
Counseling

\section{Introduction}

More than 50-million children under the age of 5 years in the developing world are wasted, $27 \%$ of children are underweight and $32 \%$ are stunted.[1] Chronic malnutrition continues to be a serious problem in Central America where $23 \%$ of children under 5 years are stunted.[2] In the Dominican Republican, 3.7\% of children under 5 years are underweight and $10 \%$ are stunted; [2] however, this prevalence is thought to be higher in rural areas of the country. Undernutrition reduces a child's chance of survival, while also hindering optimal health and growth. One of the Millennium Development Goals (MDG) to address global hardships calls for a two-thirds reduction in mortality of children less than 5 years of age by 2015.[3] In light of the role of malnutrition in disease burden, this MDG cannot be achieved without steps to improve the nutritional status of young children.

Undernutrition has major public health consequences including increased mortality and disease burden as well as decreased cognitive development and economic productivity. In a comprehensive analysis of global health burden, researchers found that malnutrition was responsible for $21 \%$ of worldwide deaths in children under 5.[4] Because of the integral role of nutrition in immune function, children with poor nutritional status are more likely to contract diarrhea, malaria and respiratory infection and more likely to suffer from these illnesses for a longer duration.[5] Additionally, malnourished children have reduced intellectual ability and years of schooling. Associations have been found between taller stature and higher cognitive performance which is thought to be due to better nutritional status during periods of brain development.[5] Furthermore, individuals that were malnourished as children lose more than $10 \%$ of lifetime earnings and countries lose at least $2-3 \%$ of their Gross National Product to undernutrition.[6] More recently, research has found a link between undernutrition and susceptibility to chronic diseases in later life. In a study of men and women born in the UK, the individuals who were undernourished as infants were found to have a greater prevalence and severity of obesity, hypertension, stroke and diabetes as adults.[7] It is evident that reducing undernutrition confers significant social and economic benefits in terms of better health outcomes, improved cognitive development, and higher earnings and health in adulthood.

The cause of malnutrition is complex and multifactorial. UNICEF's strategy for improving nutrition of children is based on a conceptual framework that classifies causes of malnutrition into three levels: immediate, underlying and basic.[8] The immediate causes of malnutrition are inadequate dietary intake and disease. Inadequate intake may arise from lack of knowledge about infant feeding, food insecurity, poor appetite or eating impairments. Diseases such a HIV, infections and low birth weight or prematurity increase metabolic needs which contributes to malnutrition. 
The underlying causes or factors that contribute to the immediate causes of malnutrition are inadequate access to food (food insecurity), inadequate care for women and children, insufficient essential healthcare, inadequate nutrition knowledge and unhealthy environment. The basic causes of undernutrition are government-level policies and programs that further contribute to malnutrition and include inadequate political and economic structure, limited ecologic resources, inequities in cultural structure, and poor child health policies and services.

Because of the extent of the problem, complexity and impact of childhood undernutrition, comprehensive and effective nutrition programming is needed. Examples of nutrition programs that have been implemented throughout the world range from breastfeeding education, promotion of complementary feeding, food supplementation, micronutrient interventions, supportive strategies for families, and community strategies such as safe drinking water to reduce disease burden. In a comprehensive review of supplementary feeding programs in developing countries conducted in the 1980s, Beaton and Ghassemi showed that supplement programs for undernourished children alone showed no effect on their nutritional status.[9] A growing number of studies show that community-based nutrition programs can in fact reduce malnutrition. Caulfield et al[10] systematic review of five randomized controlled trials on complementary feeding demonstrated an increase in children's total energy intake, improved growth and improved caregivers' feeding practice. In a cross-sectional study conducted in five rural communities in the Dominican Republic, Parikh et al [11] found rates of chronic undernutrition decreased after initiation of a food-supplementation program.

\section{Objectives}

The present study was conducted to identify causes of undernutrition in a rural community of the Dominican Republic and to evaluate the effectiveness of a nutrition-supplementation program (NSP) with and without nutrition counseling.

\section{Methods}

The study was conducted in El Cercado, Dominican Republic. El Cercado is a small, farming community located in the San Juan province of the Dominican Republic, approximately 30 miles from the Haitian border. The NSP is administered by Solid Rock International, a religious-based, non-government organization, at a medical clinic in El Cercado. Children are enrolled in the program based on nutritional need and level of malnutrition. Children enrolled in the program receive a monthly supply of powdered milk and vitamin supplements in addition to medical services at the clinic. Two weeks each year, a registered dietitian not affiliated with this study from the United States volunteers at the clinic, conducting nutritional assessments and providing medical nutrition therapy including nutritional counseling. The dietitian used the Nutrition Care Process (NCP) [15] as the model for nutrition care. NCP consists of a four steps assessment, diagnosis, intervention, monitoring and evaluating[15]. As part of the intervention step, the theoretical approach used for nutrition counseling is the Social Learning Theory. This theory identifies a dynamic, reciprocal relationship between environment, the person, and behavior[15]. Ninety children are currently enrolled in the NSP.

A mixed methodology study design was utilized to study causes of malnutrition and evaluate the program effectiveness. The causes of undernutrition in the children enrolled in the NSP were examined by conducting qualitative interviews with parents. A thorough nutrition history following a semi-structured interview format was obtained by the principle investigator (PI) who is an advanced-level dietitian. The PI interviewed parents with the assistance of a translator and recorded the interview as field notes. Data from the field notes was systematically analyzed, organized, and coded according to the specific aims of the study using a modified constant comparative method of analysis.[13,14] Following immersion in the data, analysis focused on identification of emergent themes using selected quotes from participants in accordance with the principles derived by Kidd and Parchall to enhance rigor in analysis of interviews and focus groups.[15] Data were independently coded by the PI and co-investigator as a method to establish content validity.[16] Identified themes were then compared to the UNICEP conceptual framework for malnutrition.[8] Discrepancies in theme coding between the PI and co-investigator were resolved using an independent dietitian's coding.

A retrospective observational study design was used to assess the effectiveness of the NSP and determine the impact of nutritional counseling by a registered dietitian. Specifically, percentage goal weights/age of children was assessed at enrollment into NSP (preenrollment) and at various points while in the NSP (enrolled). Clinic records of children currently enrolled in the program were reviewed. Only complete records or those with preenrollment- and enrolled-data were used.

\section{Results}

Twenty-nine interviews were conducted with parents to determine causes of malnutrition. There was $100 \%$ agreement in theme coding between the PI, co-investigator and independent dietitian. Table 1 summarizes the causes of malnutrition. The most prevalent contributor of malnutrition in the study population was food insecurity (44\%). Examples of the food insecurity theme included "father injured and unable to work" and "child lives in a single-parent household." Thirty-one percent of the children studied were 
malnourished due to disease or increased metabolic need. This included children who were born prematurely, twin births and presence of parasites. Sixteen percent of the participants were suffering from malnutrition due to health policies and services reasons, reflected as inability to access assistance as a result of distance to the clinic or clinic not having adequate supplies to provide assistance. The third contributor of malnutrition found was lack of knowledge $(9 \%)$. Examples of this theme were reflected in mothers reporting never breastfeeding or weaning earlier then recommended.

Table 1. Causes of Malnutrition

\begin{tabular}{|c|c|c|}
\hline $\begin{array}{c}\text { Theme Category in the } \\
\text { UNICEF Framework }\end{array}$ & $\begin{array}{c}\text { Theme } \\
\text { Count (\%) }\end{array}$ & Theme Example \\
\hline $\begin{array}{c}\text { Immediate - } \\
\text { Disease/metabolic need }\end{array}$ & 31 & $\begin{array}{c}\text { Child born prematurely; } \\
\text { Twin birth; Parasites }\end{array}$ \\
\hline $\begin{array}{c}\text { Underlying - Food } \\
\text { Insecurity }\end{array}$ & 44 & $\begin{array}{c}\text { Father injured and } \\
\text { unable to work; broken } \\
\text { family }\end{array}$ \\
\hline $\begin{array}{c}\text { Underlying - Lack of } \\
\text { knowledge }\end{array}$ & 9 & $\begin{array}{c}\text { Early cessation or never } \\
\text { breastfeeding }\end{array}$ \\
\hline $\begin{array}{c}\text { Basic - Poor child health } \\
\text { policies and services }\end{array}$ & 16 & $\begin{array}{c}\text { Clinic remotely located; } \\
\text { clinic runs out of milk }\end{array}$ \\
\hline
\end{tabular}

A retrospective chart review was completed to evaluate program effectiveness. Of the 90 children enrolled in the program, 45 had preenrollment- and enrolled- percentage goal weights/age. Fifty percent of the participants were male and $50 \%$ were female with an average age of 2.5 years. Of the 45 children with complete data, eighty-two percent had received nutrition counseling by the volunteer dietitian. Those receiving nutrition counseling averaged one counseling session. The mean duration of enrollment in the program was 8.3 months. Weight changes by group are provided in Table 2. Overall the children enrolled in the NSP had a significant improvement in \% goal weight/age, increasing from an average of $75 \%$ to $78 \%$ goal weight/age $(p=0.013)$. However, participants who received only received milk and vitamin supplementation did not improve \% goal weight/age (MEAN pre=77.3; MEAN post $=78.1 ; \mathrm{t}=0.21 ; \mathrm{p}<.83$ ). Children who had both nutrition counseling and supplementation improved markedly $($ MEAN pre $=67.2$, MEAN post $=78.2 ; \mathrm{t}=3.01 ; \mathrm{p}<.07)$.

Table 2. Weight change in program participants

\begin{tabular}{|c|c|c|c|c|}
\hline Group & $\begin{array}{c}\text { Pre } \\
\text { \%goal } \\
\text { wt/age }\end{array}$ & $\begin{array}{c}\text { Post } \\
\text { \%goal } \\
\text { wt/age }\end{array}$ & t-value & p-value \\
\hline $\begin{array}{c}\text { All children } \\
\text { enrolled in the } \\
\text { NSP (n=45) }\end{array}$ & 75.3 & 78.1 & -2.60 & 0.013 \\
\hline $\begin{array}{c}\text { Children receiving } \\
\text { only } \\
\text { supplementation } \\
\text { (n=8) }\end{array}$ & 77.9 & 78.1 & -0.21 & 0.838 \\
\hline $\begin{array}{c}\text { Children receiving } \\
\text { supplementation + } \\
\text { nutrition } \\
\text { counseling (n=37) }\end{array}$ & 72.2 & 78.2 & -3.07 & 0.007 \\
\hline
\end{tabular}

\section{Discussion}

Causes of malnutrition in this study were consistent with the complexity of malnutrition emphasized in the literature. Multiple causes of malnutrition were found. Immediate causes of malnutrition shown were disease and increased metabolic need as illustrated by children with parasites, born prematurely or a twin birth. Lack of knowledge and food insecurity was underlying causes that contributed to inadequate intake. On the basic level of cause, poor child health policies and services contributed to disease and inadequate intake. Not only were there multiple causes of malnutrition but there were also multiple levels of cause. For example, mother's lack of knowledge represents the individual level, food insecurity represents the community level and the nutritional vulnerability of the area, and lack of policies and services that support maternal and child health represents the government level. The implications are that a nutrition intervention program should address multiple causes and levels in order to be most effective.

This study found that the nutrition-supplementation program evaluated was effective in improving participants' nutrition status. Milk/nutrient supplementation alone, however, was not effective in increasing $\%$ goal weight/age. Nutritional counseling in conjunction with nutrition supplementation resulted in a significant improvement in weight status. As such, overall the overall improvement appears to be accounted for by the registered dietitian's intervention. 'Due to the multifactorial and complex nature of malnutrition, it is felt this program is successful when it provides multiple interventions including food supplementation, access to child health services and a dietitian's intervention to increase mother's knowledge of infant feeding practices.

There are several recommendations for future intervention. On the individual level, mothers would benefit from classes on recommended infant feeding methods including breastfeeding duration and complementary foods to increase knowledge. At the program level, sustaining multiple intervention will greatly enhance the program. In particular, employing a dietitian full-time for the program or having a community educator trained in nutrition would ensure continuous monitoring and education. At the government level, policies are needed to support this nutritionally vulnerable community and improve services for maternal and child health such as a nationally supported food assistance program or emergency food aid program.

This study's convenience, nonprobability sample was small and was not representative of the broader population of the Dominican Republic. Furthermore, social desirability bias may have been present in mothers' responses in the interviews. However, findings from this study increase understanding of causes of malnutrition in rural Dominican Republic and help to establish intervention of a registered dietitian as an essential component of an effective nutrition supplementation program. Thus, intervening at the UNICEP 
underlying level by increasing knowledge can improve outcomes even when an immediate cause intervention of increasing food availability did not.

\section{Conclusions}

Multiple factors contributed to malnutrition in this rural population in the Dominican Republic including food insecurity, disease and increased metabolic need, lack of knowledge and poor child health policies and services. As such, treatment of malnutrition should include multiple interventions. Paramount to program effectiveness is providing nutrition counseling with nutrition supplementation.

\section{REFERENCES}

[1] UNICEF. Progress for children: A world fit for children statistical review 2007, Online available:http://www.unicef.org/progressforchildren/2007n6/ files/Progress_for_Children_-_No._6.pdf

[2] UNDATA. Malnutrition prevalence, weight for age (\% of children under 5) 2011, Online available:http://data.un.org/Data.aspx?q=dominican+republi $\mathrm{c}+$ malnutrition\&d=WDI\& $\mathrm{f}=$ Indicator_Code:SH.STA.MAL N.ZS;Country_Code:DOM\&c=2,4,5\&s=Country_Name:asc, Year:desc \&v=1

[3] United Nations. End poverty millennium development goals 2015, Online available: http://www.un.org/millenniumgoals/bkgd.shtml

[4] R. E. Black, L. H. Allen, Z. A. Bhutta, L. E. Caulfield, M. de Onis, M. Ezzati, C. Mathers, J. Rivera. Maternal and child undernutrition study group maternal and child undernutrition 1: global and regional exposures and health consequences, Lancet, 371, 243-260, 2008.

[5] M. J. Manary, N. W. Solomons. Public health aspects of undernutrition. In: Public Health Nutrition, The Nutrition Society Oxford, 2004.
[6] R. Martinez, A. Fernandez, The cost of hunger: Social and economic impact of child undernutrition in Central America and the Dominican Republic, ECLAC, 2008

[7] K. M. Godfrey, D. Barker, Fetal nutrition and adult disease, American Journal of Clinical Nutrition, 71(5), 12442-1352s, 2000 .

[8] UNICEF. Strategy to reduce maternal and child undernutrition, Online available: http://www.unicef.org/eapro/Strategy_to_reduce_maternal_a nd_child_undernutrition.pdf

[9] G. H. Beaton, H. Ghassemi. Supplementary feeding program for young children in developing countries, American Journal of Clinical Nutrition, 35, 884-916. 1982.

[10] L. E. Caulfield, S. L. Huffman, E. G. Piwoz. Interventions to improve intake of complementary foods by infants 6 to 12 months of age in developing countries: impact on growth and on the prevalence of malnutrition and potential contribution to child survival, Food and Nutrition Bulletin, 20, 183-200, 1999.

[11] K. Parikh, G. Marein-Efron, S. Huang, G. O’Hare, R. Finalle, S. S. Shah. Nutritional status of children after a food-supplementation program integrated with routine health care through mobile clinics in migrant communities in the Dominican Republic, American Journal of Tropical Medicine Hygiene, 83(3), 559-564, 2010.

[12] Academy of Nutrition and Dietetics. (2012). International Dietetics \& Nutrition Terminology (IDNT) Reference Manual, $4^{\text {th }}$ ed. Chicago: Academy of Nutrition and Dietetics.

[13] Denzin NK and Lincoln YS. (2011). The SAGE handbook of qualitative research, $4^{\text {th }} \mathrm{ed}$. Los Angeles: SAGE.

[14] Y. S. Lincoln, E. G. Guba. Establishing trustworthiness. National Inquiry, 2, 289-331, 1985.

[15] P. S. Kidd, M. B. Parshall. Getting the focus and the group: enhancing analytical rigor in focus group research, Qualitative Health Research, 10(3), 293-308, 2000.

[16] M. R. Lynn. Determination and quantification of content validity. Nursing Research, 35(6), 382-386, 1986. 